\title{
Comparação entre estudantes universitários quanto à participação no programa de coleta seletiva e à consciência ambiental na gestão de resíduos domésticos
}

Comparison among university students regarding participation in selective collection program and environmental consciousness in household waste management

Comparación entre estudiantes universitarios en cuanto a la participación en el programa de recolección selectiva y la conciencia ambiental en la gestión de residuos domésticos

Maria Julia Navarro Kassim Graduanda em Engenharia Agronômica, Faculdade de Ciências Agrárias e Tecnológicas - Universidade Estadual Paulista (FCAT/UNESP), campus de Dracena, Brasil. mjkassim_enfermagem@hotmail.com

\section{Paulo Renato Matos Lopes}

Professor Assistente Doutor, Faculdade de Ciências Agrárias e Tecnológicas - Universidade Estadual Paulista (FCAT/UNESP), campus de Dracena, Brasil. plopes@dracena.unesp.br

Zuleica Oliani Rossi Professora Mestre, Faculdades de Dracena (UNIFADRA), Dracena, Brasil. zurossi@hotmail.com 
RESUMO

O objetivo deste estudo foi avaliar o conhecimento e a participação da comunidade acadêmica dracenense de duas universidades distintas no programa de coleta seletiva por meio de uma pesquisa exploratória e descritiva, além de revelar os motivos mais relevantes quanto a participação ou não dos entrevistados. Os resultados demonstraram que há uma preocupação com o meio ambiente, visto que $65,90 \%$ da comunidade acadêmica realizam a segregação dos resíduos orgânicos e recicláveis. Neste sentido, destacaram-se os estudantes da UNIFADRA com maior participação efetiva $(73,0 \%)$ em comparação com alunos da UNESP $(59,5 \%)$. Dentre os principais materiais separados, estavam plásticos, orgânicos e papel. Em relação os motivos pela não adesão à coleta seletiva, os entrevistados destacaram a ausência de coleta seletiva no município e a falta de organização entre os moradores da residência. Por outro lado, o desconhecimento de quais materiais a serem separados e o desinteresse próprio pelo programa foram julgados como sendo de nenhuma ou pouca importância. Já quando avaliados os motivos pela participação, destacaram-se positivamente o comprometimento com o meio ambiente e a criação de consciência ambiental. A influência da mídia foi considerada como pouco importante. Entretanto, observou diferenças entre os estudantes das universidades para o exercício de cidadania e a geração de novas fontes de renda e empregos, cujos fatores tiveram destaque apenas para os acadêmicos da UNIFADRA.

PALAVRAS-CHAVE: Educação ambiental. Políticas públicas. Reaproveitamento. Reciclagem.

\begin{abstract}
The purpose of this study was to evaluate the knowledge and the participation of Dracena's academic community from two different universities in selective collection program. An exploratory and descriptive research was done to reveal the most relevant reasons for interviewees participation or not in the program. Results showed that there is a concern with the environment, since $65.90 \%$ of academic community segregate organic and recyclable waste. It was highlighted that UNIFADRA students had highest effective participation (73.0\%) compared to UNESP students (59.5\%). Among the main separate materials were plastic, organic and paper. Regarding the reasons for nonadherence to the selective collection, interviewees highlighted the absence of selective collection and the lack of organization in residence. On the other hand, the lack of knowledge on materials separated and the self-interest were judged with little importance. When reasons for participation were evaluated, the environment commitment and the creation of environmental awareness were positively regarded. Media influence was considered as minor factor. However, it observed differences among university students in citizenship exercise and generation of new sources of income and jobs, whose factors were highlighted only for UNIFADRA scholars.
\end{abstract}

KEYWORDS: Environmental education. Public policies. Reuse. Recycling.

\title{
RESUMEN
}

El objetivo de este estudio fue evaluar el conocimiento y la participación de la comunidad académica de dos universidades distintas em Dracena en el programa de recolección selectiva a través de una investigación exploratoria y descriptiva, además de revelar los motivos más relevantes en cuanto a la participación o no de los entrevistados. Los resultados demostraron que hay una preocupación con el medio ambiente, ya que el $65,90 \%$ de la comunidad académica realiza la segregación de los residuos orgánicos y reciclables. En este sentido, se destacaron los estudiantes de UNIFADRA con mayor participación efectiva $(73,0 \%)$ en comparación con alumnos de la UNESP (59,5\%). Entre los principales materiales separados, estaban plásticos, orgánicos y papel. En relación a los motivos por la no adhesión a la colecta selectiva, los entrevistados destacaron la ausencia de colecta selectiva en el municipio y la falta de organización entre los residentes de la residencia. Por otro lado, el desconocimiento de qué materiales a ser separados y el desinterés propio por el programa fueron juzgados como de ninguna o poca importancia. Cuando se evaluaron los motivos por la participación, se destacaron positivamente el compromiso con el medio ambiente y la creación de conciencia ambiental. La influencia de los medios de comunicación fue considerada como poco importante. Sin embargo, observó diferencias entre los estudiantes de las universidades para el ejercicio de ciudadanía y la generación de nuevas fuentes de ingresos y empleos, cuyos factores sólo se destacaron para los académicos de la UNIFADRA.

PALABRAS CLAVE: Educación ambiental. Políticas públicas. Reaprovechamiento. Reciclaje. 


\section{INTRODUÇÃO}

Atualmente, o ser humano começa a despertar para o impacto negativo que o modelo de produção causa no ambiente. A geração de resíduos não pode ser desvinculada do desenvolvimento da humanidade. Entretanto, foi a partir da Revolução Industrial, no início do século XVIII, que além de provocar o aumento populacional em áreas urbanas, aumentou também a produção de resíduos gerados pela sociedade. O Brasil experimentou, nas últimas duas décadas, um expressivo desenvolvimento social e econômico e, juntamente com ele, veio o aumento do poder aquisitivo, aumentando o poder de compra e, consequentemente, a geração de resíduos (CORRÊA et al., 2015).

Neste sentido, encontra-se a preocupação quanto à disposição final dos resíduos sólidos urbanos. O tema teve maior destaque a partir do encontro de países na Conferência das Nações Unidas sobre o Ambiente e o Desenvolvimento (Rio-92). A partir de 2007, após o relatório do Painel Intergovernamental sobre Mudanças do Clima (IPCC), novos fatores associados ao gerenciamento de resíduos sólidos e seus impactos, como emissão de gás metano em lixões e aterros sanitários e episódios de enchentes, decorrentes do manejo inadequado, fizeram com que se ampliasse a agenda dos governos e da sociedade (BESEN et al.,2014).

Assim, as diretrizes relativas à gestão integrada e ao gerenciamento de resíduos sólidos em no país são estabelecidas pela Política Nacional Dos Resíduos Sólidos (PNRS) - Lei № 12.305/2010 (BRASIL, 2010), assim como seus princípios, objetivos e instrumentos.

Devido à falta e/ou a má gestão dos resíduos sólidos urbanos, têm acontecido recorrentes impactos negativos no meio ambiente, provocando danos ao solo, ao ar às águas superficiais e subterrâneas, ocasionando prejuízos em diversos ecossistemas (GOMES, 2014).

A coleta seletiva e a reciclagem são atividades que contribuem para a sustentabilidade urbana, influenciando diretamente na saúde humana e ambiental. Enquanto a coleta de resíduos no Brasil é um serviço público, atribuído pela Constituição Federal aos municípios, a reciclagem, é uma atividade que geralmente pertence ao setor privado. Contudo, ambas são interdependentes e se completam, pois possibilitam o desenvolvimento sustentável destes centros e promovem economia no uso de recursos naturais, reduzindo significativamente 0 volume de resíduos a ser descartado no meio e, consequentemente, seu potencial de contaminação e a emissão de gases de efeito estufa (BESEN et al.,2014).

A coleta seletiva consiste num sistema de recolhimento de materiais recicláveis como: papéis, vidros, plásticos, metais, entre outros. São previamente segregados na fonte geradora, e destinados a um sistema de triagem onde ocorre separação por cores, tamanhos, densidade, aspecto e composição química. Após, os resíduos são comercializados para indústrias recicladoras ou a sucateiros, sendo novamente introduzidos no ciclo produtivo (VILHENA, 2013).

Em 2006, apenas 451 (8,2\%) municípios brasileiros desenvolvem programas de coleta seletiva, sendo a maioria localizada nas regiões Sul e Sudeste (RIBEIRO e BESEN, 2006). Todavia, o número de municípios participantes vem aumentando, atingindo 840 (15,3\%) no ano de 2011 assim obtendo um aumento expressivo de mais de $86 \%$ em cinco anos (VILHENA, 2013). 
Portanto, o incentivo de políticas públicas junto a um planejamento adequado de educação ambiental torna-se uma importante ferramenta para sensibilização da população acerca de gestão de resíduos sólidos urbanos, culminando com efetiva participação social em programas ambientais como a coleta seletiva.

Nesse contexto, o objetivo do estudo foi analisar a compreensão da comunidade acadêmica dracenense de duas universidades distintas na gestão de resíduos domésticos. É esperado que, com essa análise, surjam estratégias e políticas de saúde públicas aplicadas à educação ambiental e conscientização da população.

\section{METODOLOGIA}

A pesquisa foi realizada no município de Dracena-SP, localizado a latitude $21048^{\prime} 48^{\prime \prime} \mathrm{S}$ e longitude 51953'55" W, na Faculdade de Dracena (FUNDEC) e na Faculdade de Ciências Agrárias e Tecnológicas - FCAT (UNESP). Os estudantes foram escolhidos de acordo com diferentes perfis socioeconômicos e cultural, sendo a primeira uma instituição particular e a segunda uma instituição pública.

O método baseou-se em uma pesquisa exploratória e descritiva pela aplicação de um questionário referente à gestão dos resíduos nas residências e ao mau gerenciamento destes materiais. Assim, foram estabelecidas relações entre os hábitos dos diferentes estudantes em relação ao seu perfil socioeconômico e cultural, além de demonstrar os motivos mais relevantes pelos quais as pessoas participam ou não do programa de coleta seletiva do município.

O questionário foi distribuído e coletado de sala em sala nas duas universidades. Posteriormente, os dados foram analisados e interpretados a fim de diagnosticar os principais problemas relacionados a cada comunidade e desenvolver estratégias direcionadas quanto à destinação adequada dos resíduos sólidos urbanos.

Participaram da pesquisa 395 pessoas, sendo 184 de acadêmicos da UNIFADRA e 211 da UNESP. Um questionário com 24 questões foi aplicado, abrangendo 215 pessoas do sexo feminino e 180 do sexo masculino.

Para este trabalho foram consideradas as questões 1, 8, 9, 12 e 13 apresentadas abaixo: 
1. Universidade

( ) UNIFADRA

( ) UNESP

8. Há a separação entre os matérias recicláveis e os resíduos orgânicos na sua residência? ( ) Sim ( ) Não ( ) Raramente

9. Se separa, qual(s) o(s) tipo(s) de material(s) separado(s)?

( ) Não separo ( ) Todos os materiais citados

( ) Alumínio ( ) Papel ( ) Vidro

( ) Metal ( ) Plástico ( ) Orgânicos

12. Qual o grau de importância destes motivos faz/faria você NÃO participar do programa de coleta seletiva?

*responder os itens de A a F de acordo com a escala: Sem importância (Muito fraco), Pouca importância (Fraco), Neutra (Médio), Importante (Forte) e Muito importante (Muito forte).

A. Ausência de coleta seletiva no município

B. Baixa geração de recicláveis na residência

C. Falta de organização entre os moradores da residência

D. Desconhecimento de quais materiais podem ser separados

E. Desinteresse próprio pela programa de coleta seletiva

F. Tempo disponível para separação dos materiais

13. Qual o grau de importância destes motivos faz/faria você PARTICIPAR efetivamente do programa de coleta seletiva?

*responder os itens de A a F de acordo com a escala: Sem importância (Muito fraco), Pouca importância (Fraco), Neutra (Médio), Importante (Forte) e Muito importante (Muito forte).

A. Criação de consciência ambiental entre os moradores da residência

B. Comprometimento com o meio ambiente

C. Exercício da cidadania

D. Geração de novas fontes de renda e empregos

E. Influência da mídia (TV, internet, jornais, etc.)

F. Incentivo de políticas públicas, como programa de coleta seletiva.

Os resultados foram expressos em gráficos e tabelas revelando o grau de importância de diferentes motivos entre os entrevistados para sua participação efetiva ou não no programa de coleta seletiva (Questões 13 e 12, respectivamente). Além disso, foi possível estabelecer relações entre: a separação de materiais recicláveis nas residências com a universidade do estudante (Questões 1 e 8) e com o tipo de material separado por cada entrevistado (Questões 1 e 9$)$. 


\section{da Alta Paulista}

\section{RESULTADOS E DISCUSSÃO}

Em relação à separação de materiais recicláveis dos resíduos orgânicos nos domicílios (Questão 8), os resultados revelaram a maior parte da comunidade acadêmica faz a separação de resíduos em sua residência (65,9\%), sendo que somente $24,6 \%$ alegaram não e $9,5 \%$ raramente participam do programa de coleta seletiva do município (Figura 1).

Na Tabela 1 destacou-se a população acadêmica da UNIFADRA com maior participação na separação dos resíduos domésticos (73,0\%) em comparação com alunos da UNESP $(59,5 \%)$.

Figura 1. Relação entre os estudantes universitários e a separação de resíduos nos domicílios.

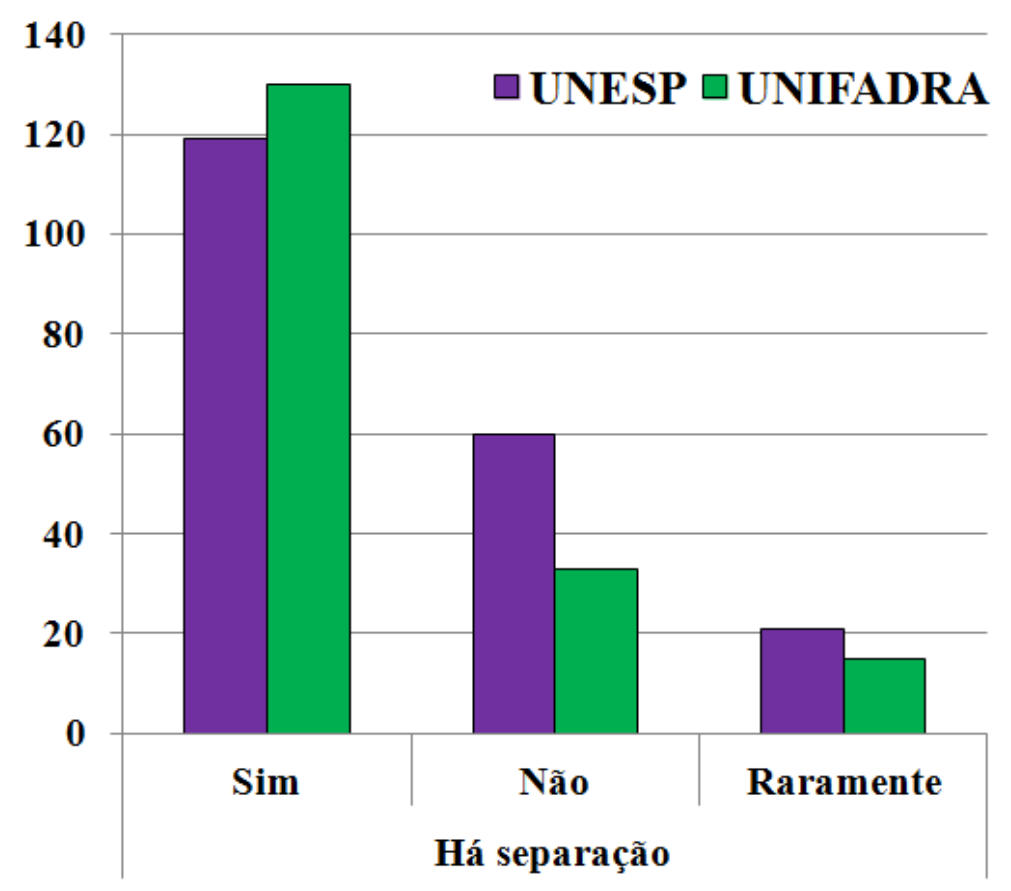

Tabela 1. Percentuais da relação entre estudantes universitários e a separação de resíduos nos domicílios.

\begin{tabular}{|l|l|l|l|}
\hline Há separação? & UNESP & UNIFADRA & TOTAL \\
\hline Sim & $59,5 \%$ & $73,0 \%$ & $\mathbf{6 5 , 9 \%}$ \\
\hline Não & $30,0 \%$ & $18,5 \%$ & $\mathbf{2 4 , 6 \%}$ \\
\hline Raramente & $10,5 \%$ & $8,4 \%$ & $\mathbf{9 , 5 \%}$ \\
\hline
\end{tabular}

Quando correlacionados os dados acima com o tipo de resíduos separados pelos entrevistados (Questões 8 e 9), observou-se que os principais materiais separados são plásticos, orgânicos e papel (Figura 2).

Portanto, sabendo da necessidade de mudanças no comportamento e nos hábitos da sociedade moderna, os desafios da construção social e discussão conjunta desta problemática criam um campo fértil para o desenvolvimento de ações de educação ambiental. Logo, estes 


\section{da Alta Paulista}

resultados possibilitam a realização de um planejamento detalhado com diretrizes focadas no público-alvo.

Figura 2. Relação entre os estudantes universitários e os tipos de materiais separados como resíduos nos domicílios

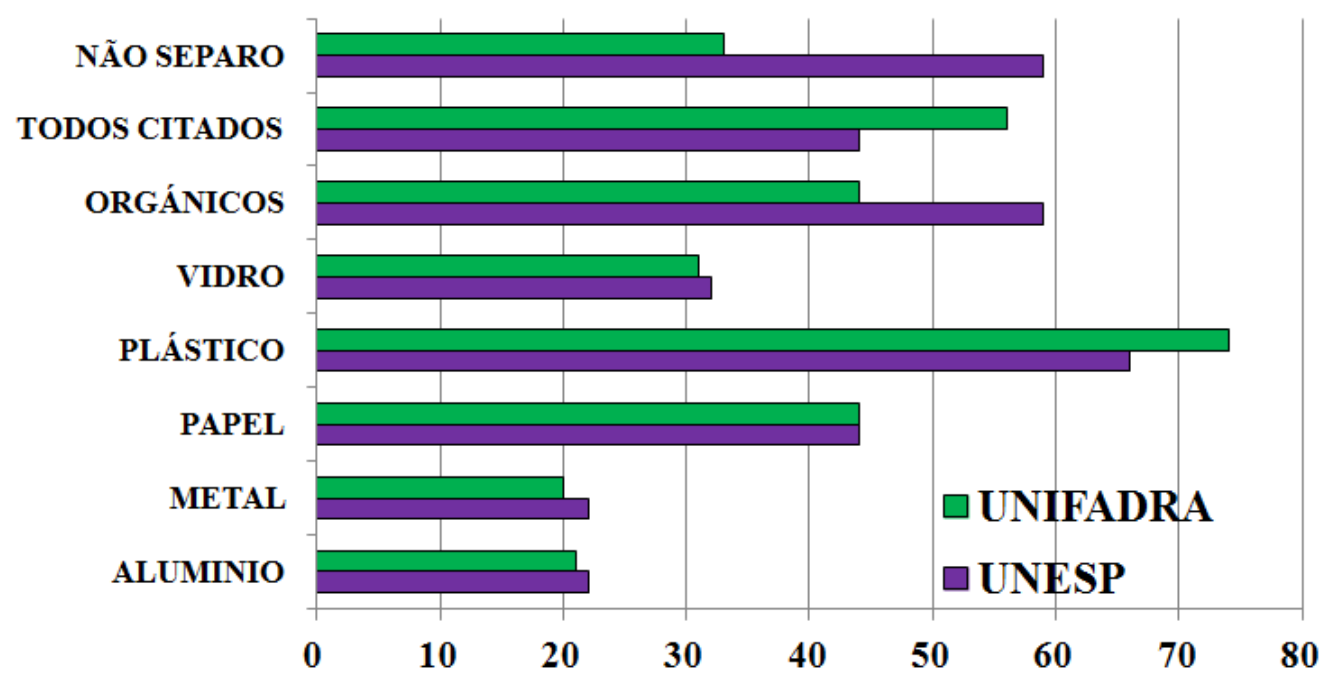

Além disso, foram avaliados os motivos dos entrevistados das duas comunidades acadêmicas acerca dos motivos que as pessoas participam ou não do programa de coleta seletiva pela separação de seus resíduos gerados nas residências.

Nas Figuras 3 e 4, apresentam-se os resultados obtidos por meio da Questão 12 que relaciona os motivos pela não adesão à coleta seletiva para alunos da UNESP e da UNIFADRA, respectivamente.

Assim, foi possível notar que $56,8 \%$ dos acadêmicos da UNESP julgam a coleta seletiva no município importante ou muito importante (Figura $3 \mathrm{~A}$ ) e que $40,7 \%$ não consideram a quantidade de resíduos gerados um fator limitante para sua participação (Figura 3B).

Constatou-se ainda que a organização entre os moradores da residência é um motivo que apresentou bastante variação, uma vez que há praticamente uma igualdade no grau de relevância dessa resposta (Figura $3 \mathrm{C}$ ). Este resultado pode ser devido à maioria desses estudantes serem oriundos de outras cidades e, portanto, moram em casas compartilhadas com outros alunos, como em "repúblicas". 


\section{da Alta Paulista}

Figura 3. Grau de importância dos motivos que faz/faria você não participar do programa de coleta seletiva para a comunidade acadêmica da UNESP. (A) ausência de coleta seletiva no município; (B) baixa geração de recicláveis na residência; (C) falta de organização entre os moradores da residência; (D) desconhecimento de quais materiais podem ser separados; (E) desinteresse próprio pela programa de coleta seletiva; (F) tempo disponível para separação dos materiais.

A

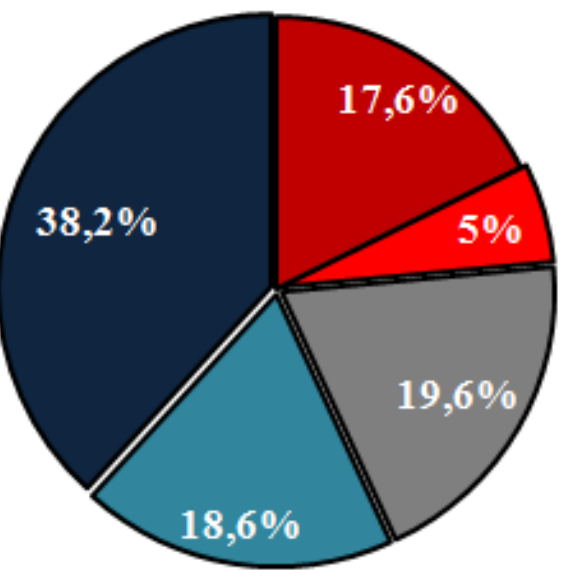

$C$

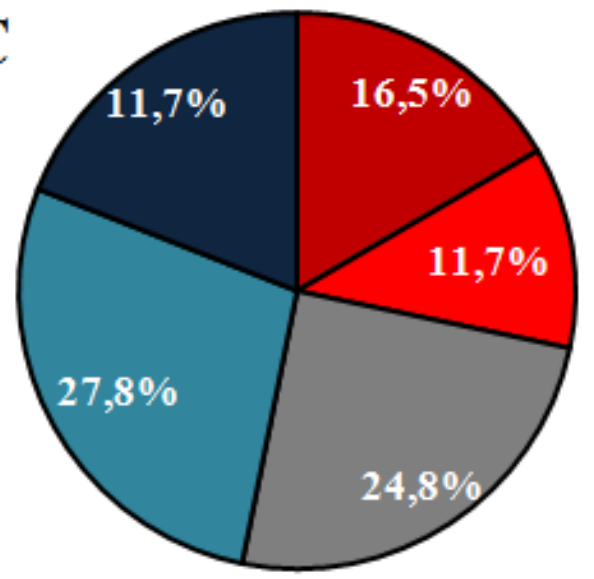

$\mathbf{E}$

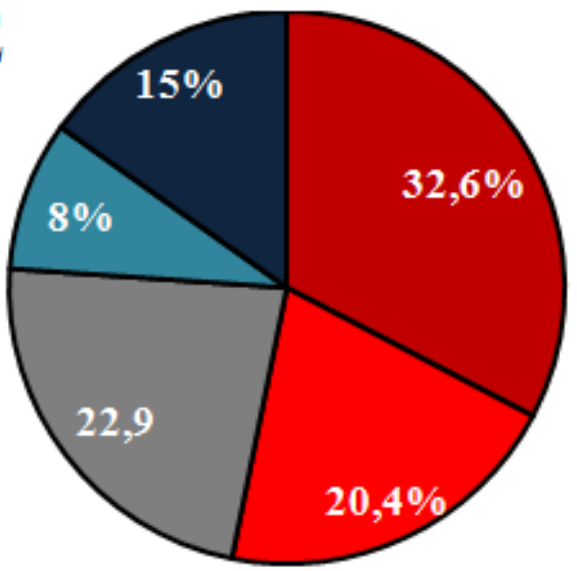

ロSem importância
口Pouca importânca
B

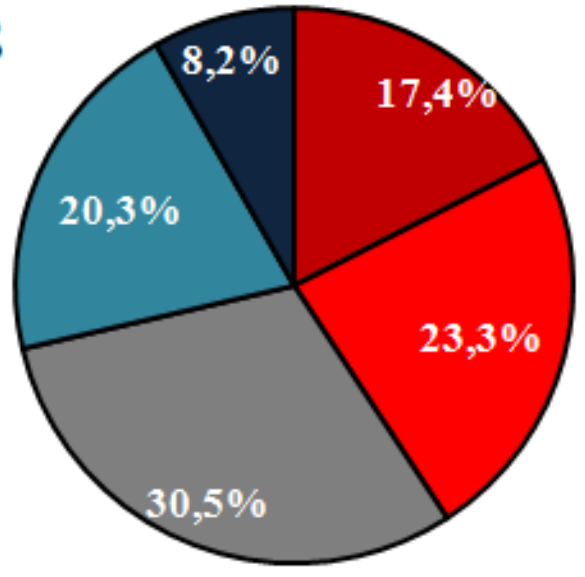

D

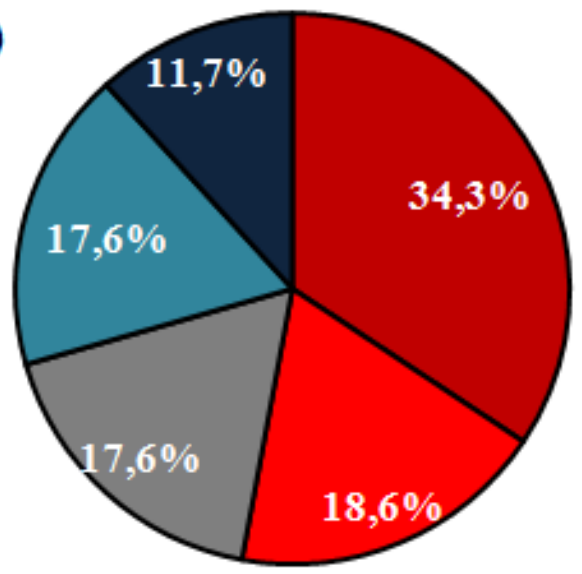

$\mathbf{F}$

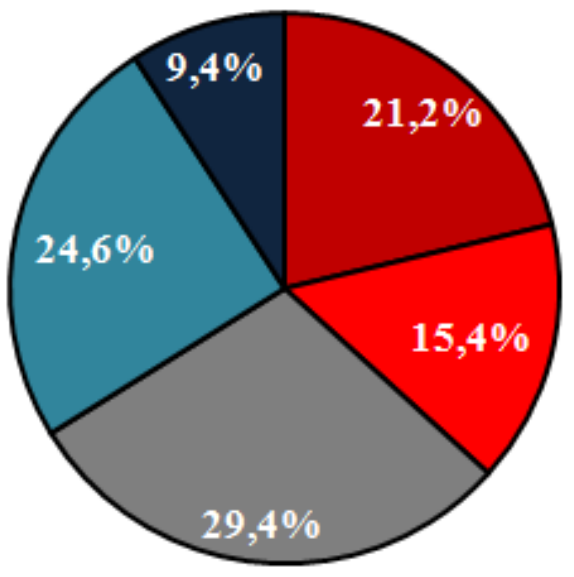

QNeutra $\square$ Importante $\square$ Muito importante 
Figura 4. Grau de importância dos motivos que faz/faria você não participar do programa de coleta seletiva para a comunidade acadêmica da UNIFADRA. (A) ausência de coleta seletiva no município; (B) baixa geração de recicláveis na residência; (C) falta de organização entre os moradores da residência; (D) desconhecimento de quais materiais podem ser separados; $(\mathrm{E})$ desinteresse próprio pela programa de coleta seletiva; $(\mathrm{F})$ tempo disponível para separação dos materiais.

A

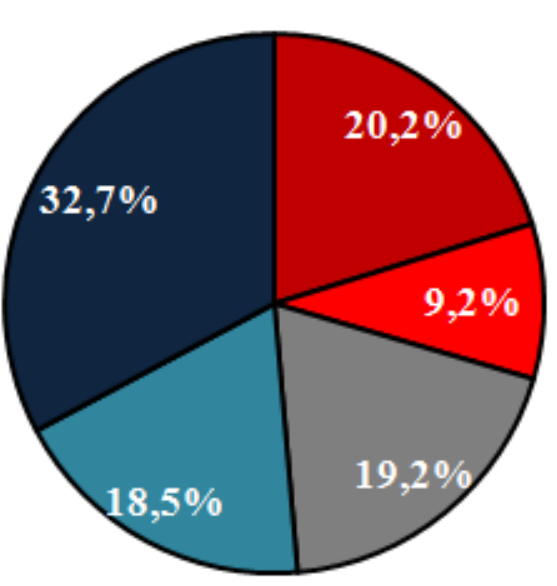

$\mathcal{C}$

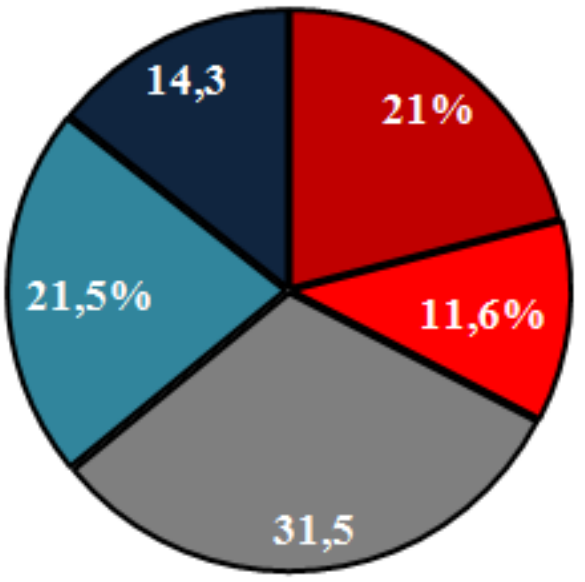

$\mathbf{E}$

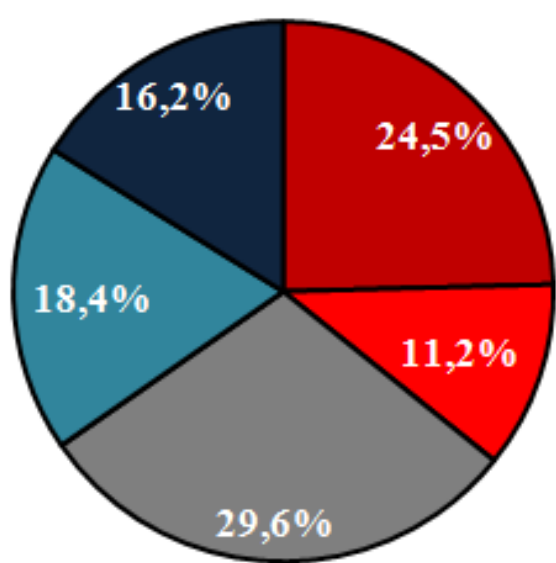

B

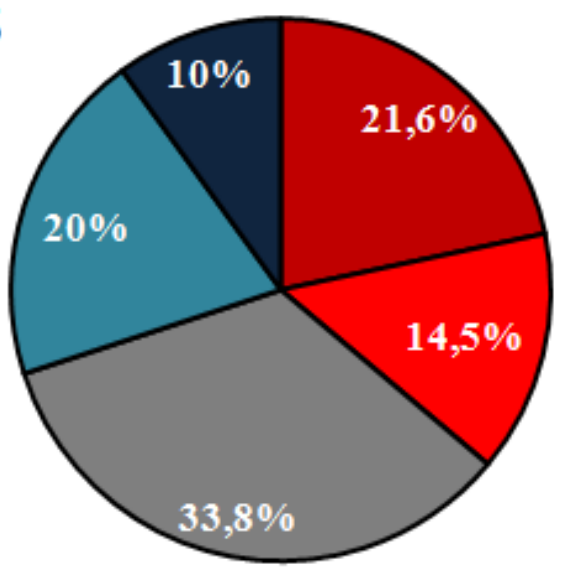

D

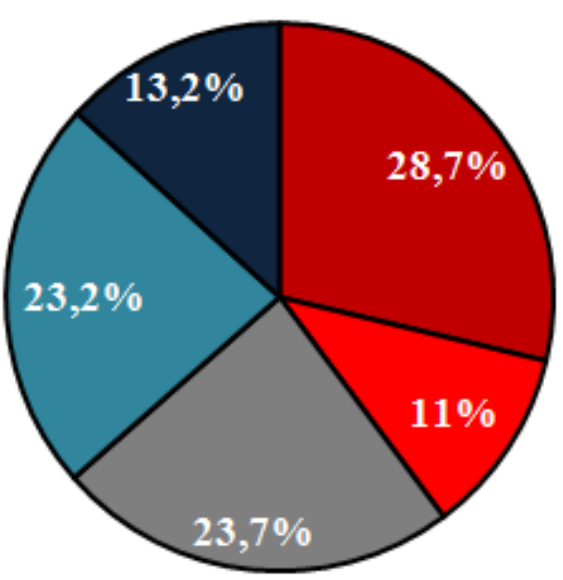

$\mathbf{F}$

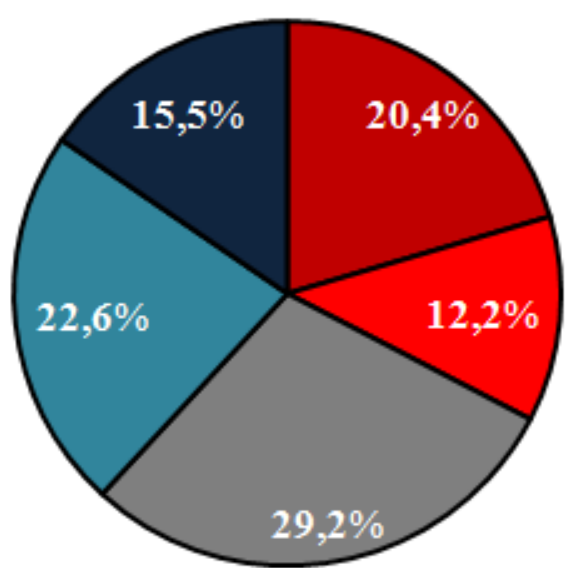

QNeutra aImportante aMuito importante

\section{口Sem importância QPouca importânca}

Em se tratando do desconhecimento sobre quais materiais podem ser recicláveis, este fator não se apresentou como um gargalo para a adesão dos entrevistados da UNESP à separação 
dos resíduos. Visto que a maioria das embalagens apresentam símbolos e frases de incentivo à reciclagem, 52,9\% consideraram este motivo como sendo não importante ou pouco importante (Figura 3D).

Por fim, a maioria dos alunos da UNESP revelou que possui interesse por programas de coleta seletiva $(53,0 \%$, Figura $3 E$ ) e um terço dos entrevistados não consideram o tempo como um agravante para a sua realização (36,6\%, Figura 3F).

Por outro lado, na Figura 4 estão expressos os resultados para os acadêmicos da UNIFADRA. Neste sentido, 51,2\% julgam a coleta seletiva no município importante ou muito importante (Figura 4A), sendo que $36,1 \%$ não consideram a quantidade de resíduos gerados um fator limitante para sua participação (Figura 4B).

Para este caso, constatou-se que a organização entre os moradores da residência foi um motivo não importante ou pouco importante para $32,6 \%$ das pessoas. Tal resultado contrapõe a resposta encontrada pelos estudantes da UNESP (Figura 3C), uma vez que a comunidade da UNIFADRA geralmente reside com a família no município ou na região de Dracena e, portanto, muitos já possuem o hábito cultural no conhecimento e participação no programa de coleta seletiva (Figura 4C).

Quanto ao desconhecimento de quais materiais podem ser separados, 39,7\% acharam não importante ou pouco importante, em vista que já é cultural dessa região a participação da coleta seletiva. (Figura 4D). Contudo, o desinteresse pela coleta seletiva apresentou bastante variação, uma vez que há praticamente uma igualdade no grau de relevância dessa resposta para os graus de importância avaliados (Figura 4E).

Por fim, 38,1\% dos alunos da UNIFADRA julgam ser importante ou muito importante em relação ao tempo disponível para separação dos materiais (Figura 4F).

A pesquisa também propôs analisar os motivos pelos quais os entrevistados participam do programa de coleta seletiva. Da mesma forma como os níveis apresentados na questão anterior, os resultados obtidos por meio da Questão 13 para as comunidades acadêmicas da UNESP e da UNIFADRA estão apresentados nas Figuras 5 e 6 , respectivamente. 


\section{Fórum Ambiental}

\section{da Alta Paulista}

Figura 5. Grau de importância dos motivos que faz/faria você participar efetivamente do programa de coleta seletiva para a comunidade acadêmica da UNESP. (A) criação de consciência ambiental entre os moradores da residência; (B) comprometimento com o meio ambiente; (C) exercício da cidadania; (D) geração de novas fontes de renda e empregos; (E) influência da mídia (TV, internet, jornais, etc.); (F) incentivo de políticas públicas, como programa de coleta seletiva.
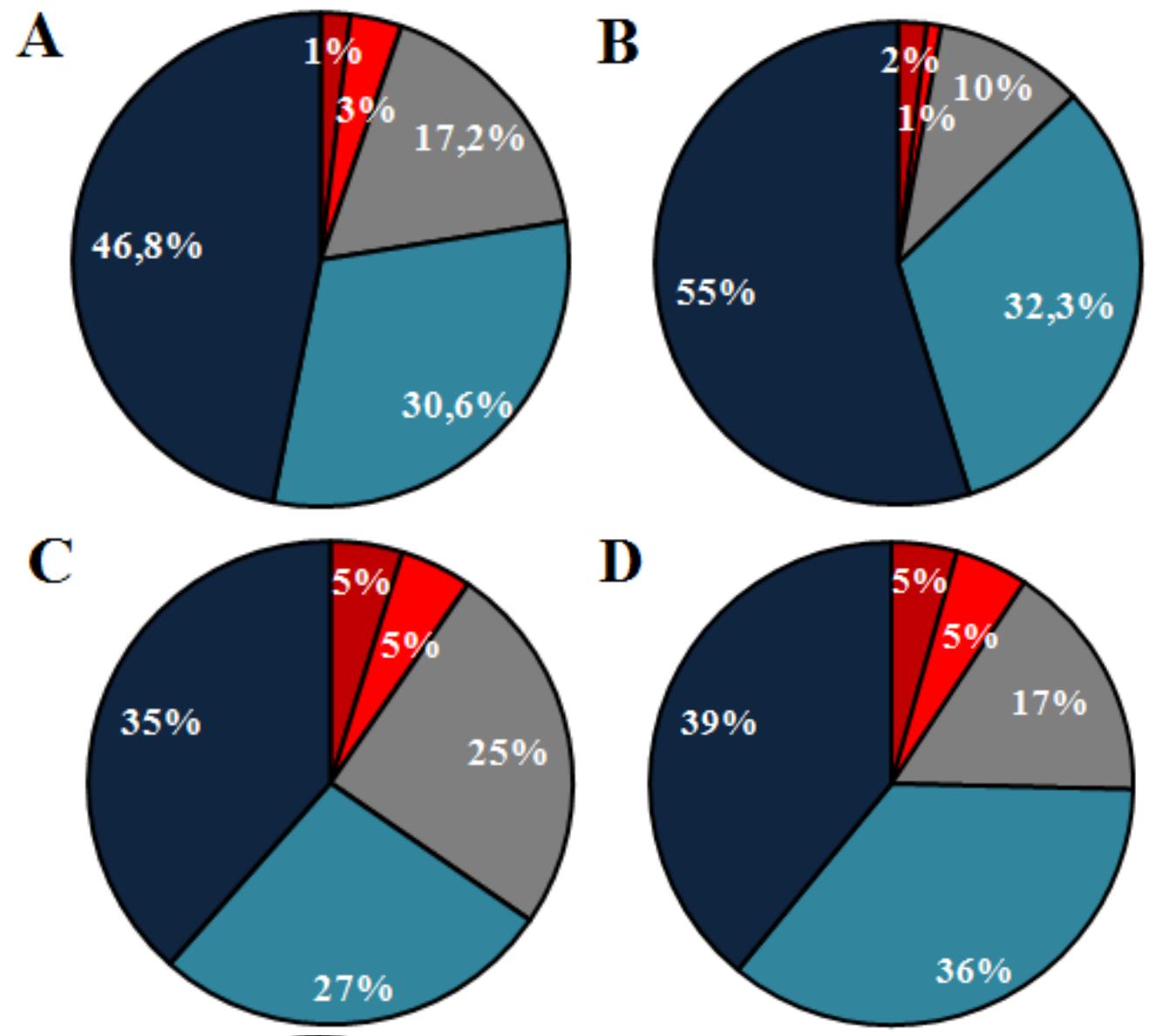

E

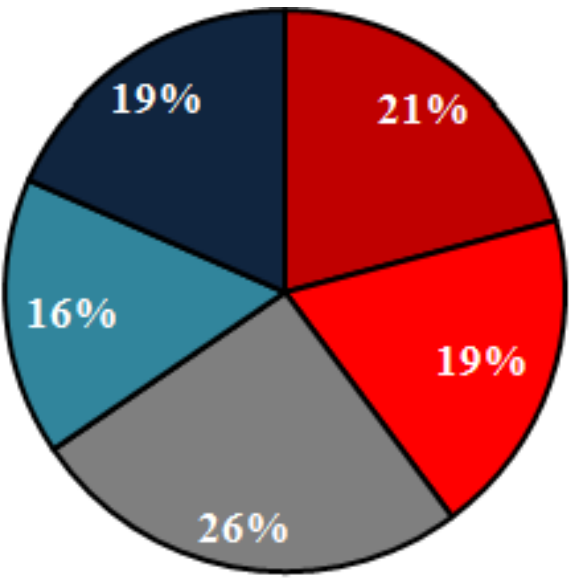

ロSem importância
口Pouca importânca
F

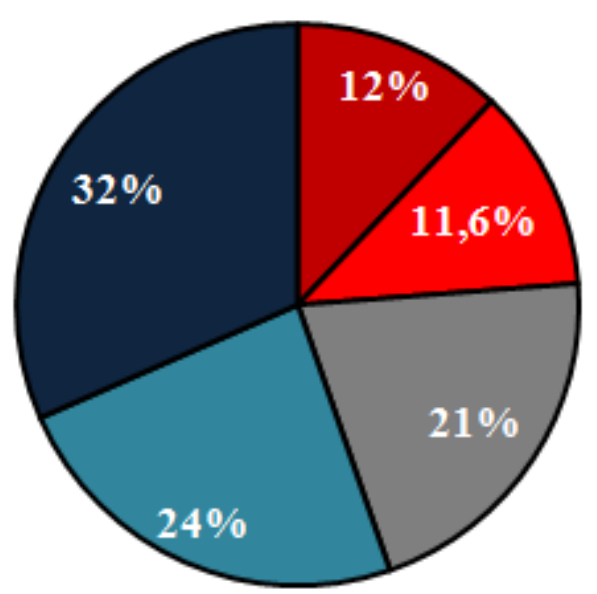

QNeutra Importante
QMuito importante 


\section{Fórum Ambiental}

\section{da Alta Paulista}

Figura 6. Grau de importância dos motivos que faz/faria você participar efetivamente do programa de coleta seletiva para a comunidade acadêmica da UNIFADRA. (A) criação de consciência ambiental entre os moradores da residência; (B) comprometimento com o meio ambiente; (C) exercício da cidadania; (D) geração de novas fontes de renda e empregos; (E) influência da mídia (TV, internet, jornais, etc.); (F) incentivo de políticas públicas, como programa de coleta seletiva.

A

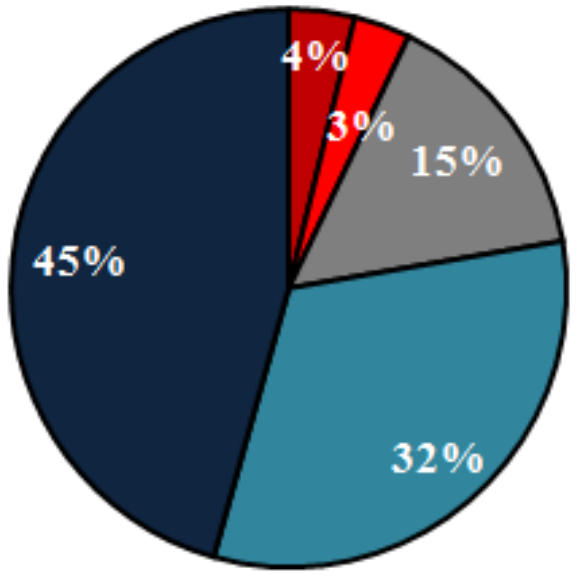

C

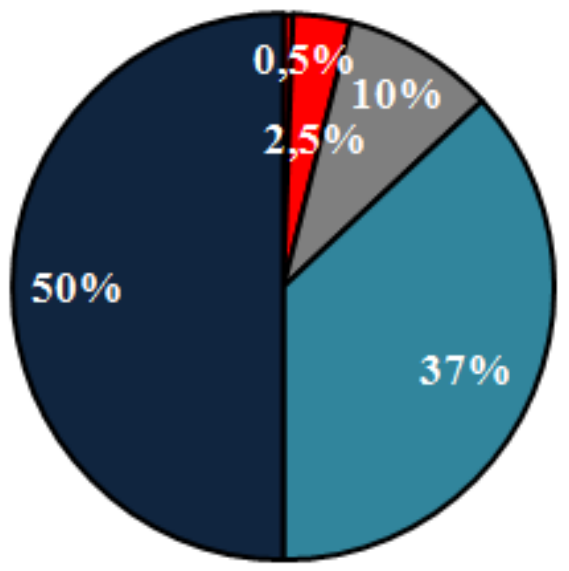

$\mathbf{E}$

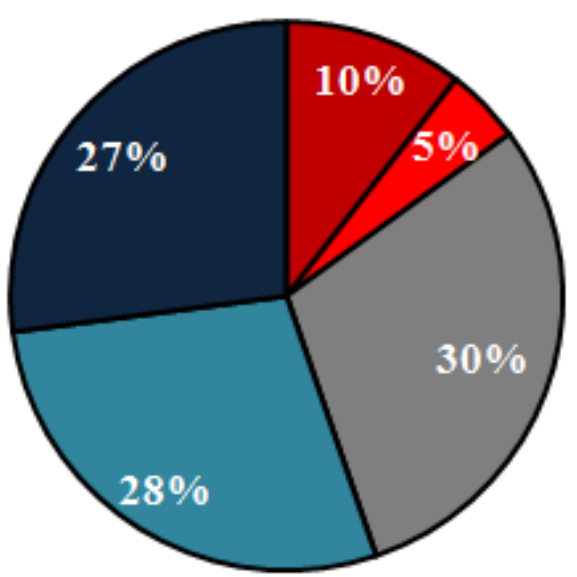

\section{ロSem importância पPouca importânca}

B

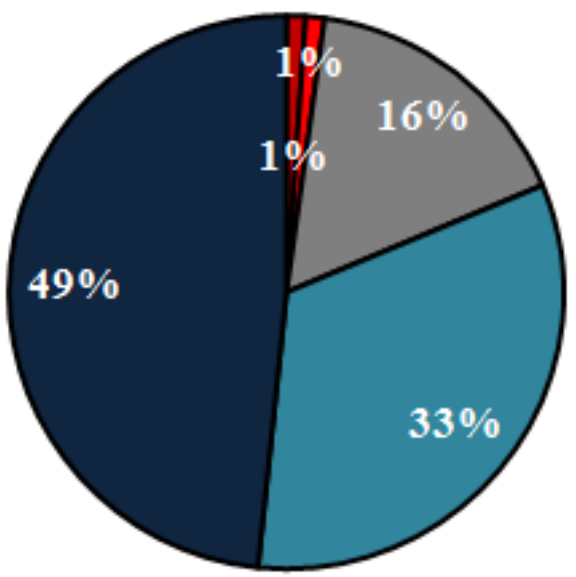

D

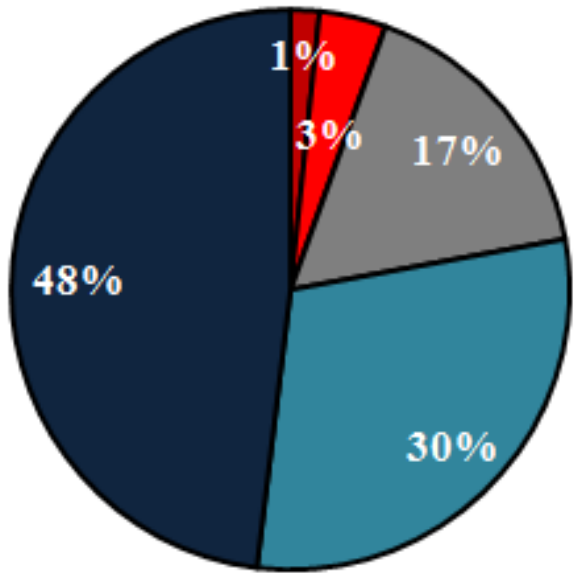

$\mathbf{F}$

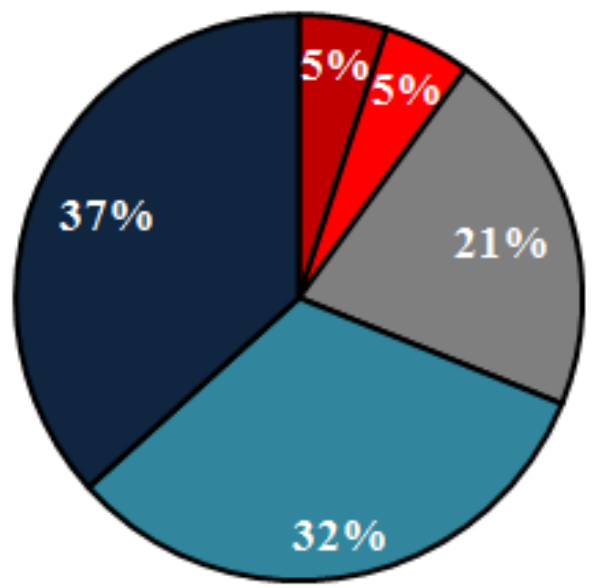

QNeutra QImportante $\square$ Muito importante

Observa-se, nas Figuras 5A e 6A, que a criação de consciência ambiental entre os acadêmicos de ambas as universidades é um fator fundamental, visto que $77,4 \%$ dos estudantes da UNESP e $77,0 \%$ da UNIFADRA revelaram ser este um fator importante ou muito importante. 
De forma ainda mais expressiva está o comprometimento com o meio ambiente como motivo importante ou muito importante para os entrevistados (87,3\% UNESP e $82,0 \%$ UNIADRA), sendo a minoria dos estudantes que julgaram como pouco ou sem importância ou pouco importante (3,0\% UNESP e 2,0\% UNIADRA) (Figuras 5B e 6B).

$O$ exercício da cidadania também foi considerado um bom motivo para adesão ao programa de coleta seletiva pelos estudantes da UNESP e UNIFADRA que foi indicado como importante ou muito importante por $62,0 \%$ e $87,0 \%$, respectivamente (Figuras $5 \mathrm{C}$ e $6 \mathrm{C}$ ). O mesmo foi revelado para geração de novas fontes de renda e empregos, apresentado nas Figuras 5D e 6D (75,0\% UNESP e 78,0\% UNIADRA).

De uma maneira geral, a mídia influencia parcialmente as pessoas em separar os resíduos nas residências. O resultado apresentado nas Figuras $5 E$ e $6 E$ demonstram uma distribuição semelhante entre os níveis de relevância entre as duas universidades. Por fim, o estudo revelou que o incentivo de políticas públicas é um dos fatores significativos para a participação da população no programa, uma vez que foi avaliado como importante ou muito importante para $57,0 \%$ dos estudantes da UNESP e 69,0\% da UNIFADRA (Figuras 5F e 6F).

\section{CONCLUSÃO}

Concluiu-se que, dentre os entrevistados nas comunidades acadêmicas das duas universidades, há uma preocupação entre a separação dos resíduos orgânicos e recicláveis. Entretanto, verificou-se que os estudantes UNIFADRA são mais participativos à coleta seletiva em comparação aos da UNESP. Este resultado pode estar baseado na falta de hábito cultural e familiar dos unespianos, uma vez que estes alunos muitas vezes são oriundos de outras regiões do país onde não há coleta seletiva. Também, pode-se citar a falta de organização entre as pessoas da casa como importante motivo para a não separação dos resíduos.

Contudo, quanto à participação no programa, a maioria dos entrevistados avaliou os motivos julgados como importantes para adesão à coleta seletiva, destacando o comprometimento com o meio ambiente e a criação de consciência ambiental entre os moradores da residência. Salienta-se que a mídia não se demonstrou como um fator significativo, já o incentivo de políticas públicas, como programa de coleta seletiva, foi considerado para a maioria os entrevistados. Logo, torna-se essencial a criação de estratégias e o desenvolvimento de ações diretas para que a abrangência deste importante programa socioambiental atinja uma maior parcela da população e seja ainda mais eficiente em reduzir a geração de resíduos domésticos.

\section{AGRADECIMENTO}

Os autores agradecem a Faculdade de Ciências Agrárias e Tecnológicas - Universidade Estadual Paulista (FCAT/UNESP), as Faculdades de Dracena (UNIFADRA), a Pró-Reitoria de Extensão Universitária da UNESP (PROEX/UNESP) e o GAIA - Grupo de Ação em Impactos Ambientais da FCAT/UNESP.

\section{REFERÊNCIAS BIBLIOGRÁFICAS}

BESEN, G.R. et al. Coleta seletiva na região metropolitana de São Paulo: impactos da Política Nacional de Resíduos Sólidos. Ambiente \& Sociedade, São Paulo, v. XVII, n. 3, p. 259-278, 2014. 
BRASIL. Lei no 12.305, de 2 de agosto de 2010. Institui a Política Nacional de Resíduos Sólidos e dá outras providências. Disponível em: <http://www.planalto.gov.br/ccivil_03/_atO2007-2010/2010/lei/l12305.htm>. Acesso em: 20 jun. 2017.

BRINGHENTI, J.R. Participação social em programas de coleta seletiva de resíduos sólidos urbanos. Engenharia Sanitária e Ambiental, São Paulo, v.16, 2011.

CÔRREA, L.B. et al. Análise social de um Programa de Coleta Seletiva de Resíduos Sólidos Domiciliares. Revista Monografias Ambientais, Santa Maria, v. 14, n. 2, p.193-201, 2015.

GOMES, M.H.S.C. et al. Política nacional de resíduos sólidos: perspectivas de cumprimento da Lei 12.305/2010 nos municípios brasileiros, municípios paulistas e municípios da região do ABC. Revista de Administração da Universidade Federal de Santa Maria, Santa Maria, v. 7, Edição Especial, p. 93-110, 2014.

RIBEIRO, H.; BESEN, G.R. Panorama da coleta seletiva no Brasil: desafios e perspectivas a partir de três estudos de caso. Revista de Gestão Integrada em saúde do Trabalho e Meio Ambiente - INTERFACEHS, São Paulo, v.2, n.4, p.118, 2007.

VILHENA, A. Guia da coleta seletiva de lixo. São Paulo: CEMPRE, 2013. Disponível em: <http://cempre.org.br/upload/arq/o_19q4hmlrq1n8o166v1pl4onjv2ba.pdf>. Acesso em: 5 jun., 2017. 